\title{
Facial Plastic Training During Residency Program and the Factors Affecting it - A Descriptive Study of Saudi Residents
}

\author{
Almuhaya Reham ${ }^{1 *}$, Alharethy Sami ${ }^{2}$, Aldosari Badi ${ }^{2}$, Alkarzae Mohammed ${ }^{2}$ and Yara Alanazi ${ }^{2}$ \\ ${ }^{1}$ Depatment of Otorhinolaryngology, Prince Sultan Military Medical City, Riyadh, Kingdom of Saudi Arabia \\ ${ }^{2}$ Department of Otorhinolaryngology, College of Medicine, King Saud University, Riyadh, Kingdom of Saudi Arabia
}

*Corresponding author: Almuhaya Reham, Depatment of Otorhinolaryngology, Prince Sultan Military Medical City, Riyadh, Kingdom of Saudi Arabia

\begin{abstract}
ARTICLE INFO
Received: 幽 September 30, 2019

Published: 畿 October 15, 2019

Citation: Almuhaya Reham, Alharethy Sami, Aldosari Badi, Alkarzae Mohammed, Yara Alanazi. Facial Plastic Training During Residency Program and the Factors Affecting it - A Descriptive Study of Saudi Residents. Biomed J Sci \& Tech Res 22(1)-2019. BJSTR. MS.ID.003687.
\end{abstract}

Keywords: Residency; Facial plastic; Surgery; Training; Otolaryngology

\section{ABSTRACT}

Introduction: The residency training program plays an important factor affecting the resident's choice of the study area and the need for fellowship training. A lot of factors may play roles in training quality, for example, the number of trainers, the training hospital's specialty or restricted policies in the selection of cases. The number of facial plastic surgery cases, particularly cosmetic cases, has recently increased. This enhance to improve the facial plastic training during the residency program.

Method: A cross-sectional study was conducted at King Saud University, Saudi Arabia after the approval of the institutional review board committee of the same institute. The study included all male and female otorhinolaryngology-head and neck surgery residents in the four approved residency programs in the kingdom as well as plastic surgery residents rotating in facial plastic surgery in Saudi Arabia from July to September 2018 (the end of the training year); a questionnaire evaluating their exposure \& satisfaction was emailed to all of them.

Result: Complete responses were collected from 87 of 219 eligible participants $(\sim 40 \%)$ in the year 2018 . The residents mainly participated as assistants in open septoplasty and open and closed rhinoplasty surgery. Conversely, a majority of the residents never attended or participated in otoplasty, blepharoplasty, facelift, local flap surgery, Botox, or filler procedures. Most of the residents thought that their training was insufficient and unsatisfying $(n=43,49.43 \%),(n=5,5.75 \%)$ believed that their training was sufficient, $(\mathrm{n}=21,24.14 \%)$ did not think it was adequate but they were satisfied, and $(\mathrm{n}=18$, $20.69 \%$ ) were not exposed to a facial plastic surgery at all.

Conclusion: Most of the resident think that their training was insufficient. The majority of them never attended or participated in otoplasty, blepharoplasty, facelift, local flap surgery, Botox or filler procedures.

\section{Introduction}

\section{Background}

Otorhinolaryngology-Head and Neck Surgery (ORL-H\&N) in the Kingdom of Saudi Arabia is a five-year structured training program, upon completion of which trainees will have gained fundamental knowledge, clinical skills, and an understanding of professional behaviour, it is considered the largest training program in the Gulf region. The Saudi Commission for Health Specialties
(SCFHS) is adopting the Canadian Medical Education Directives for Specialists (Can MEDS) framework to set up the core curriculum of all training programs, including the Saudi Board Certification in Otorhinolaryngology - Head and Neck Surgery. Upon completion of the residency training program, graduating residents will be able to function as independent otolaryngologist-head and neck surgeons, enabling them to pursue careers in general otolaryngology successfully or to proceed with subspecialty fellowship training [1]. 
The residency training program plays an important factor affecting the resident's choice of the study area and the need for fellowship training. The impact of residency training in otolaryngology subspecialty may be positive or negative; thus, it is crucial to receive balanced training in all divisions. A lot of factors may play roles in training quality, for example, the number of trainers, the training hospital's specialty or restricted policies in the selection of cases.

The number of facial plastic surgery cases, particularly cosmetic cases, has recently increased. This enhance to improve the facial plastic training during the residency program [3]. A study undertaken by Osguthorpe et al. found that no significant differences in cosmetic surgery results between surgeries performed by the residents or staff who trained them except that residents required more time [4]. However, residents need sufficient training \& increased exposure to these procedures to reach this goal [3]. In Saudi (ORL-H\&N) residency program, the facial plastic rotation is mandatory to do in the (R3-R5) levels for three months, with a minimum number of cases for each procedure and recommended courses to be taken [1].

\section{Objectives}

There is no recent study has assessed resident's exposure to facial plastic surgery during the residency program, especially in Saudi Arabia. Therefore, it was found worthwhile to analyse the change in the knowledge and attitudes of (ORL-H\&N) program residents after introducing the rotation on facial plastic surgery in the new curriculum.

\section{Methods}

A cross-sectional study was conducted at King Saud University, Saudi Arabia after the approval of the institutional review board committee of the same institute. The study included all male and female otorhinolaryngology-head and neck surgery residents in the four approved residency programs in the kingdom as well as plastic surgery residents rotating in facial plastic surgery in Saudi Arabia from July to September 2018 (the end of the training year); a questionnaire was emailed to all of them. Data regarding the residents' demography, duration of facial plastic surgery rotation during the residency program was collected. Also, self-reported evaluation related to facial plastic surgery procedures such as (septoplasty, rhinoplasty, otoplasty, blepharoplasty, facelift surgery, local flap, Botox, and dermal fillers), number of times attending/ participating in the previous procedures, evaluation of the training in the facial plastic surgery rotation in general and what is the reasons affecting it. Residents in the R2-R3 level were considered junior residents, whereas those in the R4-R5-R6 level were considered seniors. Residents in the R1 level were excluded from the study since they have no exposure.

\section{Results}

Complete responses were collected from 87 of 219 eligible participants $(\sim 40 \%)$ in the year 2018 . Resident distribution by the Saudi region was $(n=52,59.77 \%)$ from the central region, $(n=9$ $, 10.34 \%)$ from the eastern region, $(n=22,25.29 \%)$ from the western region, and $(n=4,4.60 \%)$ from the southern region. Otolaryngology residents represented a majority $(n=75,86.21 \%) \&$ plastic surgery residents $(n=12,13.79 \%)$. In addition, participants were predominantly male $(n=59,67.82 \%$ (VS female) $n=28,32.18 \%$ ). R2 level were ( $n=18,20.69 \%)$, R3 level were $(n=28,32.18 \%), R 4$ level were ( $n=15,17.24 \%)$, R5 level were $(n=24,27.59 \%)$, and R6 level were $(n=2,2.30 \%)$. Most residents participated in facial plastic surgery rotation at the junior level $(n=57,65.52 \%)$. Overall, $(n=$ $48,55.17 \%$ ) of our participants' facial plastic rotations were based on hospital's need, ( $n=21,24.14 \%$ ) on curriculum requirement, and $(n=18,20.69 \%)$ on personal preference. The duration of facial plastic surgery rotation for a majority of the residents was 3 months (Figure 1). Responses to questions assessing exposure and residents' role in facial plastic surgery during residency program are presented in Table 1 . The residents mainly participated as assistants in open septoplasty and open and closed rhinoplasty surgery. Conversely, a majority of the residents never attended or participated in otoplasty, blepharoplasty, facelift, local flap surgery, Botox, or filler procedures.

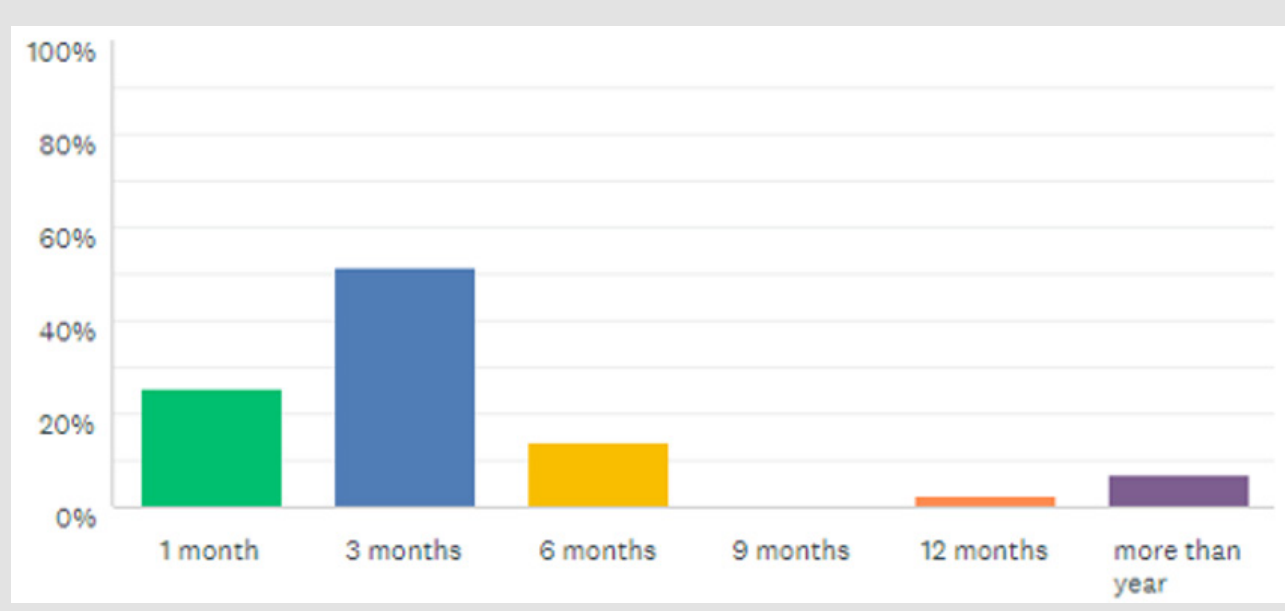

Figure 1: The duration of facial plastic rotation during residency program. 
Table 1: The residents' role in facial plastic surgery procedures during training.

\begin{tabular}{|c|c|c|c|c|}
\hline $\begin{array}{c}\text { Question: Have you attended/participated in the follow- } \\
\text { ing procedure? }\end{array}$ & As an observer & As a surgeon & As an assistant & Did not attend or participate \\
\hline Open septoplasty & $21(24.14 \%)$ & $9(10.34 \%)$ & $34(39.08 \%)$ & $23(26.44 \%)$ \\
\hline Open rhinoplasty surgery? & $16(18.39 \%)$ & $6(6.90 \%)$ & $62(71.26 \%)$ & $3(3.45 \%)$ \\
\hline Closed rhinoplasty surgery? & $16(18.39 \%)$ & $11(1264 . \%)$ & $48(55.17 \%)$ & $12(13.79 \%)$ \\
\hline Otoplasty surgery? & $15(17.24 \%)$ & $8(9.20 \%)$ & $25(28.74 \%)$ & $39(44.83 \%)$ \\
\hline Blepharoplasty surgery? & $9(10.34 \%)$ & $3(3.45 \%)$ & $11(12.64 \%)$ & $64(73.56 \%)$ \\
\hline Facelift surgery? & $4(4.60 \%)$ & $2(2.30 \%)$ & $6(6.90 \%)$ & $75(86.21 \%)$ \\
\hline Local flap surgery? & $10((\% 11.49$ & $9(10.34 \%)$ & $35(40.33 \%)$ & $33(37.93 \%)$ \\
\hline Botox/filler procedure? & $11(12.64 \%)$ & $3(3.45 \%)$ & $5(5.75 \%)$ & $68(78.16 \%)$ \\
\hline
\end{tabular}

In self-efficacy evaluation regarding the basic knowledge \& skills following the facial plastic surgery rotation, we found that most of the residents could not correct superior deviation $(n=38$, 4368. \%) and they did not know the different types of otoplasty techniques ( $\mathrm{n}=38,4368$. \%), however, most residents could correct posterior deviation $(n=51,58.62 \%)$, anterior deviation

Table 2: Results of A self-efficacy evaluation.
( $n=46,52.87 \%$ ), and caudal dislocation $(n=33,37.93 \%)$, and they knew the indications for open septoplasty $(n=43,49.43 \%)$. At the end of the rotation, $(n=19,21.84 \%)$ only can confidently perform facial analysis and the majority $(n=53,60.92 \%)$ believe that they can partially do operative planning (Table 2).

\begin{tabular}{|c|c|c|c|}
\hline Question & Yes & No & Partially \\
\hline Do you know the indications for open septoplasty? & $43(49.43 \%)$ & $7(8.05 \%)$ & $37(42.53 \%)$ \\
\hline Can you correct superior deviation? & $17(19.54 \%)$ & $38(4368 . \%)$ & $32(36.78 \%)$ \\
\hline Can you correct anterior deviation? & $46(52.87 \%)$ & $20(22.99 \%)$ & $21(24.14 \%)$ \\
\hline Can you correct posterior deviation? & $51(58.62 \%)$ & $20(22.99 \%)$ & $16(18.39 \%)$ \\
\hline Can you correct caudal dislocation? & $33(37.93 \%)$ & $28(32.18 \%)$ & $26(29.89 \%)$ \\
\hline Are you confident in performing the facial analysis? & $19(21.84 \%)$ & $29(33.33 \%)$ & $39(44.83 \%)$ \\
\hline Can you do operative planning for a rhinoplasty patient? & $17(19.54 \%)$ & $17(19.54 \%)$ & $53(60.92 \%)$ \\
\hline Do you know the types of closed rhinoplasty techniques? & $25(28.74 \%)$ & $28(32.18 \%)$ & $34(39.08 \%)$ \\
\hline Do you know the types of otoplasty techniques? & $27(31.03 \%)$ & $38(43.68 \%)$ & $22(25.29 \%)$ \\
\hline
\end{tabular}

We evaluated resident satisfaction and the primary factors affecting their training. Most of the residents thought that their training was insufficient and unsatisfying $(n=43,49.43 \%),(n=5$, $5.75 \%)$ believed that their training was sufficient, $(n=21,24.14 \%)$ did not think it was adequate but they were satisfied, and $(n=18$, $20.69 \%$ ) were not exposed to a facial plastic surgery at all (Table 3). A majority felt that their training was affected by consultant

Table 3: Resident satisfaction by region.

\begin{tabular}{|c|c|c|c|c|}
\hline & Central region & Eastern region & Western region & Southern region \\
\hline No exposure & $4(7.69 \%)$ & $5(55 \%)$ & $8(36.36 \%)$ & $1(25 \%)$ \\
\hline $\begin{array}{c}\text { Insufficient, and } \\
\text { unsatisfying }\end{array}$ & $26(50 \%)$ & $3(33.3 \%)$ & $12(54.54 \%)$ & $2(50 \%)$ \\
\hline Insufficient but satisfying & $18(34.61 \%)$ & $0(0 \%)$ & $2(9.09 \%)$ & $1(25 \%)$ \\
\hline Sufficient & $4(7.69 \%)$ & $1(11.1 \%)$ & $0(0 \%)$ & $0(0 \%)$ \\
\hline
\end{tabular}

concern of the outcome ( $n=57,65.52 \%),(n=23,26.44 \%)$ think it may play a role, whereas only $(n=7,8.05 \%)$ disagreed. The number of training consultants was considered the second factor affecting the training in facial plastic surgery rotation during the residency program $(n=46,52.87 \%)$. However, the least effecting element was the presence of fellows $(n=8,9.20 \%)$ (Figure 2$)$. 


\section{The reasons behind insufficient training}

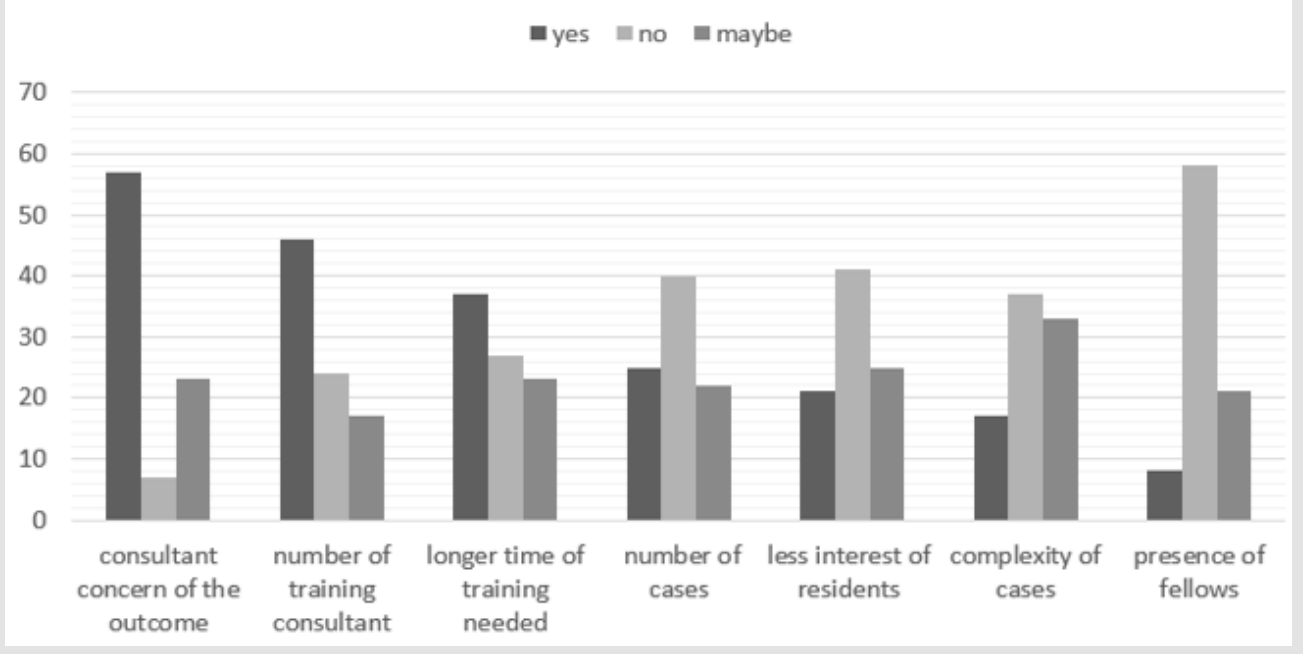

Figure 2: Primary factors affecting resident training.

\section{Discussion}

Residency programs are critical in developing competencies that residents are expected to demonstrate to help them in patients' care, improve their knowledge and communication skills, and competently perform all medical and invasive procedures essential to their area of practice [5] It is much easier to acquire new surgical skills in a residency program than after the completion of the residency training [6].

Safely learning the necessary surgical skills are considered the most significant challenge and requires a training period [6]; thus, the residents must be provided with reliable and effective methods to help them achieve such skills. Having adequate knowledge, undergoing a period of preceptorship with multiple courses, and working as members of a high-performance team, all play a role in gaining the necessary experience to ensure optimum outcomes [6]. The Accreditation Council for Graduate Medical Education's (ACGME) suggests viewing a videotape of one's performance, receiving oral feedback, keeping logs and learning plans, performing self-assessments and quality improvement projects, and developing resident-initiated projects such as activities involving active experimentation for practice-based learning and improvement [7]. However, inadequate training during residency is one of the reasons why residents seek fellowship training [8]. But the Lack of appropriate training in basic procedures during residency program may prevent them from gaining additional skills and may affect their drive to complete their fellowship training as well [8].

Surgical training in otolaryngology has characteristics that could minimize or enhance the magnitude of this task. These factors include many subspecialties and varied operative modes including open vs. endoscopic, microscopic, office-based procedures as well as the issues of medical otolaryngology and comfort zone [9]. The objectives of facial plastic rotation in an otolaryngology residency training program in Saudi Arabia in general, are to demonstrate adequate knowledge and surgical expertise in nasal, auricular, and lip reconstruction, functional and cosmetic rhinoplasty, blepharoplasty, and face, brow, and neck lifting. Besides, developing basic competence in non-invasive facial rejuvenation techniques, including facial augmentation, botulinum toxin (Botox) injection, laser therapy, and chemical peeling, is necessary [1].

Unfortunately, what we found is contradicting these objectives, the majority didn't have exposure to blepharoplasty, facelift or rejuvenation injections. No recent studies have discussed residents' level of exposure to surgical facial plasty to compare with our results. However, Thomas et al. in 1990 evaluated the facial plastic training in the American board of otolaryngology-head and neck surgery \& they reported a decrease in the number of facioplasty procedures performed by residents, notably brow lifts, face lifts, and otoplasties [3]. Miller R in 1994 found that United States' residents did not receive enough training in otology, facial plastic surgery, and allergy; however, they received too much training in head and neck surgery which is comparable of what we found [8].

Most of our residents thought that consultant concern of the result was the main reason for insufficient training. Conversely, studies showed that resident participation in surgery is not associated with an increase in morbidity or mortality [9-16] and based on the American College of Surgeons-NSQIP Database, operations with resident involvement had similar morbidity and lowered mortality than did those without the participation of residents, and the cosmetic surgery in particular has no difference $[4,17]$ Limitations of this study include the relatively small sample size, lack of objective tools for assessing resident knowledge and skills, the different level of residents training in facial plastic 
surgery rotations, potential recall bias attributable to inaccurate self-reporting and response bias due to nonresponders. Likewise, the current study is one of the first in our region that explores this problem with the growth of facial plastic surgery cases [18].

\section{References}

1. Saudi Board Otolayngology - Head and Neck Surgery Curriculum.

2. Thomas J, Graboyes J (1986) A Specific Curriculum in Facial Plastic Surgery: Effect on Residency Training. Arch Otolaryngology Head Neck Surg 112(1): 70-72.

3. Regan Thomas J, Ehlert T, Fenwick J (1990) Facial plastic surgery in the otolaryngology training program: An update Am J Otolaryngol 11(3):188-190.

4. Osguthorpe J, Lomax W (1985) Facial plastic surgery in an otolaryngology training program. Laryngoscope 95(10): 1255-1257.

5. Goff B, Mandel L, Lentz G, Vanblaricom A, Oelschlager AM, et al. (2005) Assessment of resident surgical skills: Is testing feasible? Am J Obstet Gynecol 192(4): 1331-1338.

6. Sachdeva AK (2005) Acquiring Skills in New Procedures and Technology Arch Surg 140(4):387.

7. Laeeq K, Weatherly RA, Carrott A, Pandian V, Cummings CW, et al (2009) Learning styles in two otolaryngology residency programs. Laryngoscope 119(12): 2360-2365.

8. Miller R (1994) Otolaryngology Residency and Fellowship Training: The Resident's Perspective. Arch Otolaryngol Head Neck Surg 120(10): 1057-1061.

9. Lim S, Parsa AT, Kim BD, Rosenow JM, Kim JY (2015) Impact of resident involvement in neurosurgery: an analysis of 8748 patients from the 2011 American College of Surgeons National Surgical Quality Improvement Program database. J Neurosurg 122: 962-970.

\section{ISSN: 2574-1241}

DOI: 10.26717/BJSTR.2019.22.003687

Almuhaya Reham. Biomed J Sci \& Tech Res

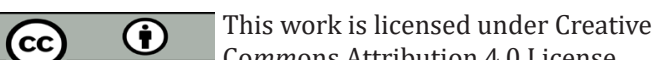

Submission Link: https://biomedres.us/submit-manuscript.php
10. Matulewicz RS, Pilecki M, Rambachan A, Kim JY, Kundu SD (2014) Impact of resident involvement on urological surgery outcomes: an analysis of 40,000 patients from the ACS NSQIP database. J Urol 192(3): 885-890.

11. Abt N, Reh D, Eisele D, Francis H, Gourin (2016) Does resident participation influence otolaryngology-head and neck surgery morbidity and mortality? Laryngoscope 126(10): 2263-2269.

12. Baskett RJ, Buth KJ, Legare JF, Hassan A, Hirisch GM, et al. (2002) Is it safe to train residents to perform cardiac surgery? Ann Thorac Surg 74(4): 1043-1048-1048-1049.

13. Coates KW, Kuehl TJ, Bachofen CG, Shull BL (2001) Analysis of surgical complications and patient outcomes in a residency training program. Am J Obstet Gynecol 184: 1380-1383-1383-1385.

14. Jan A, Riggs DR, Orlando KL, Khan FJ (2012) Surgical outcomes based on resident involvement: what is the impact on vascular surgery patients. J Surg Educ 69: 638-642.

15. Jordan SW, Mioton LM, Smetona J, Aggarwal A, Wang E, et al. (2013) Resident involvement and plastic surgery outcomes: an analysis of 10,356 patients from the American College of Surgeons National Surgical Quality Improvement Program database. Plast Reconstr Surg 131: 763-773.

16. Nguyen CT, Babineau DC, Jones JS (2008) Impact of urologic resident training on patient pain and morbidity associated with office-based cystoscopy. Urology 71:782-786.

17. Saliba A, Taher A, Tamim H, Harb AR, Mailhac A, et al. (2016) Impact of Resident Involvement in Surgery (IRIS-NSQIP): Looking at the Bigger Picture Based on the American College of Surgeons-NSQIP Database. Journal of the American College of Surgeons 222(1): 30-40.

18. (2016) Cosmetic Surgery National Data Bank Statistics. Aesthet Surg J 36(suppl 1): 1-29.

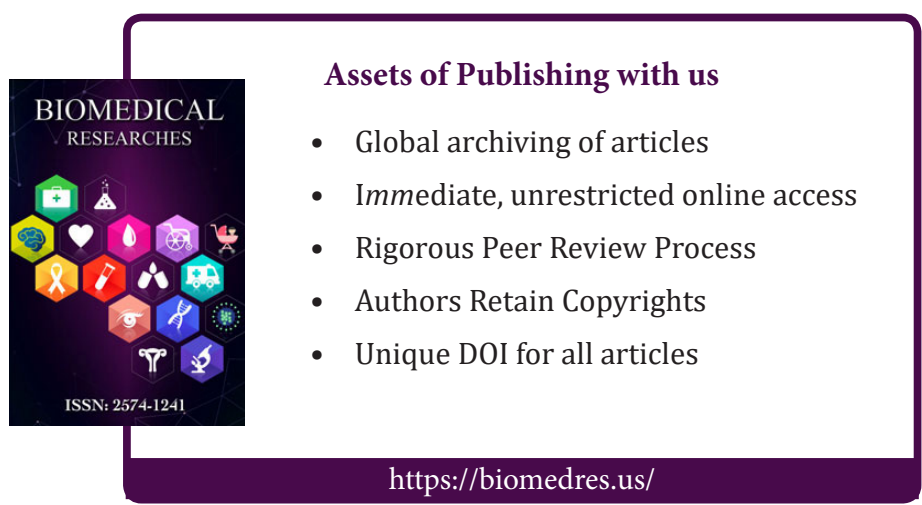

